\title{
STUDENTS' LIVED EXPERIENCE OF USING SEESAW CLASS APPLICATION IN ENGLISH I CLASS
}

\author{
Paskalina Widiastuti Ratnaningsih \\ paskalina.widiastuti.r@gmail.com \\ Musi Charitas Catholic University
}

\begin{abstract}
This paper aims at discovering students' lived experience in using Seesaw Class application in English I Class. Seesaw Class is an application for teaching-learning in the smartphone. Applications are used as the media for learning in the present era. Seesaw Class application is used to enhance English skills and components during teaching-learning activities. Various features in Seesaw Class application provide more space for students to express their ideas. The method used is a hermeneutic- phenomenology method. It focuses on the description and interpretation of lived experience. The data were gathered with in- depth interview, observation, and document review. The research was validated with triangulation. The research results are divided into empirical themes and transcendent themes. Meaning in each theme is revealed with deep understanding of the research and has the implication in the practice area. The concept discovered in this study is explained in a Venn diagram and has the implication in the theory area.
\end{abstract}

Keywords: English Class; Lived Experience; Seesaw Class Application

\section{INTRODUCTION}

The development of technology runs faster and offers various devices and applications. It influences the teaching-learning activities where technology is used as the media in learning. Ktoridou and Eteokleous in Fezile Ozdamli (2011, p. 927) state that learners use mobile and IT devices, such as mobile phones, laptops, tablet PCs in m-learning. Radcliffe et al in Laanpere et al (2013, p. 420) builds heuristic Pedagogy-Space- Technology (PST) framework in a pedagogy-driven manner. Since the focus is on the teaching-learning activity, pedagogy-driven is utilized in the classroom. Colpaert in Laanpere et al (2013, p.420) points out pedagogy-driven approach as "a detailed specification of what is needed for language-teaching and-learning purposes in a specific context, defines the most appropriate method, and finally attempts to describe the technological requirements to make it work". Mobile and IT devices support the teaching-learning process. It is as stated that mobile devices encourage innovation and abilities (Frohberg et al., 2009; Sung, Chang, Yang, 2015; Zucker \& Light, 2009, cited in Sung, Chang, Liu, 2016). The choice of appropriate device is based on the aim and context of learning.

Smartphone as a mobile device with applications inside is used widely. It is stated that the youth more engage in the use of smartphone (Stern and Wallace, cited in Chan et al, 
2017, p. 99). Hence, smartphone gets a place to be used in the learning context. Seesaw class application as one of the applications in the smartphone offers features that can enhance language learning. The features in Seesaw Class application are text, PDFs, Links/URLs, drawings, photos and videos with QR code to join the class (Hamilton, 2017). Various features can enhance English language learning. The students can also give comments or likes to the post written in the application (Hamilton, 2017). Seesaw Class application is used in this study for learning English I. English I in this context is English for Accounting.

A previous study on lived experience of using smartphone in learning context was done by Chan et al (2017). The study of lived experience that is focused on the use of Seesaw Class application has not conducted yet. Hence, this study is to fill the gap and discover the use of Seesaw Class application in English learning. The research question in this study is: What is students' lived experience of using Seesaw Class application in English I class like? This study is to describe and interpret and also to formulate the concept of lived experience in using Seesaw Class application in English I class.

\section{THEORETICAL FRAMEWORK}

Learning English puts English skills and components in context. Writing and speaking as English skills are enhanced more while using Seesaw Class application. Zamel as stated by Reid in Carter and Nunan (2001, p.29) points out that writing has been focused on process movement in which the students enhance creativity, personal writing, and fluency. Students need to get more input to enhance creativity in writing and also writing habit to be more fluent in writing. On the other hand, Levelt as stated by Bygate in Carter and Nunan (2001, p.16) divides four processes in speaking, namely conceptualization, formulation, articulation, and self-monitoring. Conceptualization as in speaking planning, formulation as in finding words and grammar, articulation as in controlling articulatory organs, selfmonitoring as in reflecting the mistakes are reinforced in the speaking process. In addition, grammar and vocabulary as English components are also used. Doughty and Williams as stated by Freeman in Carter and Nunan (2001, p.37) define focus on form is more effective in learning grammar with communicative approach. Carter in Carter and Nunan (2001, p.42) states that learning vocabulary includes word list, paired translation, and semantic sets.

Pedagogy-based approach fulfills the aim and context of learning. Colpaert (2006, p.479) states four points to be emphasized in pedagogy-based approach. The first is technology innovation and constraints must be acquired well. The second is specified system of technology is matched with pedagogical requirements. The third is evaluation of technology use in learning. The fourth is bridging technology and language pedagogy in context. Laanpere et al (2013, p.424) states four pedagogical frameworks, namely selfdirected learning (SDL), competence-based learning (CBL), collaborative knowledge building (CKB), and task-centered instructional design models. The students are independent learners to have better outcome with collaborative and task learning. 
Mobile device is synchronized in English class in this study. It is stated that "mobile learning is a type of learning whose learner is determined previously, is not in a specific location, or benefits the opportunities offered by mobile technologies" (O'Malley et al., 2003, cited in Korucu and Alkan , 2011, p. 1926). Place and time are not the obstacles in learning with m-learning. There are eleven characteristics of m-learning, namely mobile, GPRS, objects, spontaneous, connected, networked, lightweight, situated learning, informal, realistic situation, and constructivism (Eteokleous and Laouris, 2005, cited in Korucu and Alkan, 2011, p.1927). Seesaw Class application provides flexible learning with m-learning characteristics. Mobile Pedagogical Framework consists of three distinctive characteristics of m-learning, namely authenticity, collaboration, and personalization (Kearney et al., 2012, cited in Schuck, 2015, pp.2- 3). Authenticity enhances contextual learning. Collaboration is in the terms of data sharing through mobile device. Personalization is emphasized in conducting personal project in the device.

During teaching-learning process, motivation drives the students to have better learning. Brown (2007, p.85) states that motivation makes the student have goals and efforts to pursue something. Brown (2007, pp. 85-86) also divides motivation into behavioral and cognitive terms. Behavioral motivation is focused on external rewards in praise, grade, certificate, and happiness. Cognitive motivation is focused on self-esteem.

The framework of pre-understanding in this study can be seen below in Figure 1. Goal, process, and outcome work in order. Based on the goal of the research, the process involves semi m-learning since the learning does not fully use the smartphone outside the classroom. The application is also used inside the classroom. This study is based on pedagogy-driven approach in which aim and context of learning determine the technology used. After deciding the aim and context as seen in the figure, Seesaw Class application is chosen as the technology used. Bridging the use of technology and English class also enhances self-directed and task-centered learning. The outcome is language skills and components and also motivation of using application in teaching-learning activities. The outcome is explained in the form of description and interpretation and also the initial concept of using Seesaw Class application found in this study. 


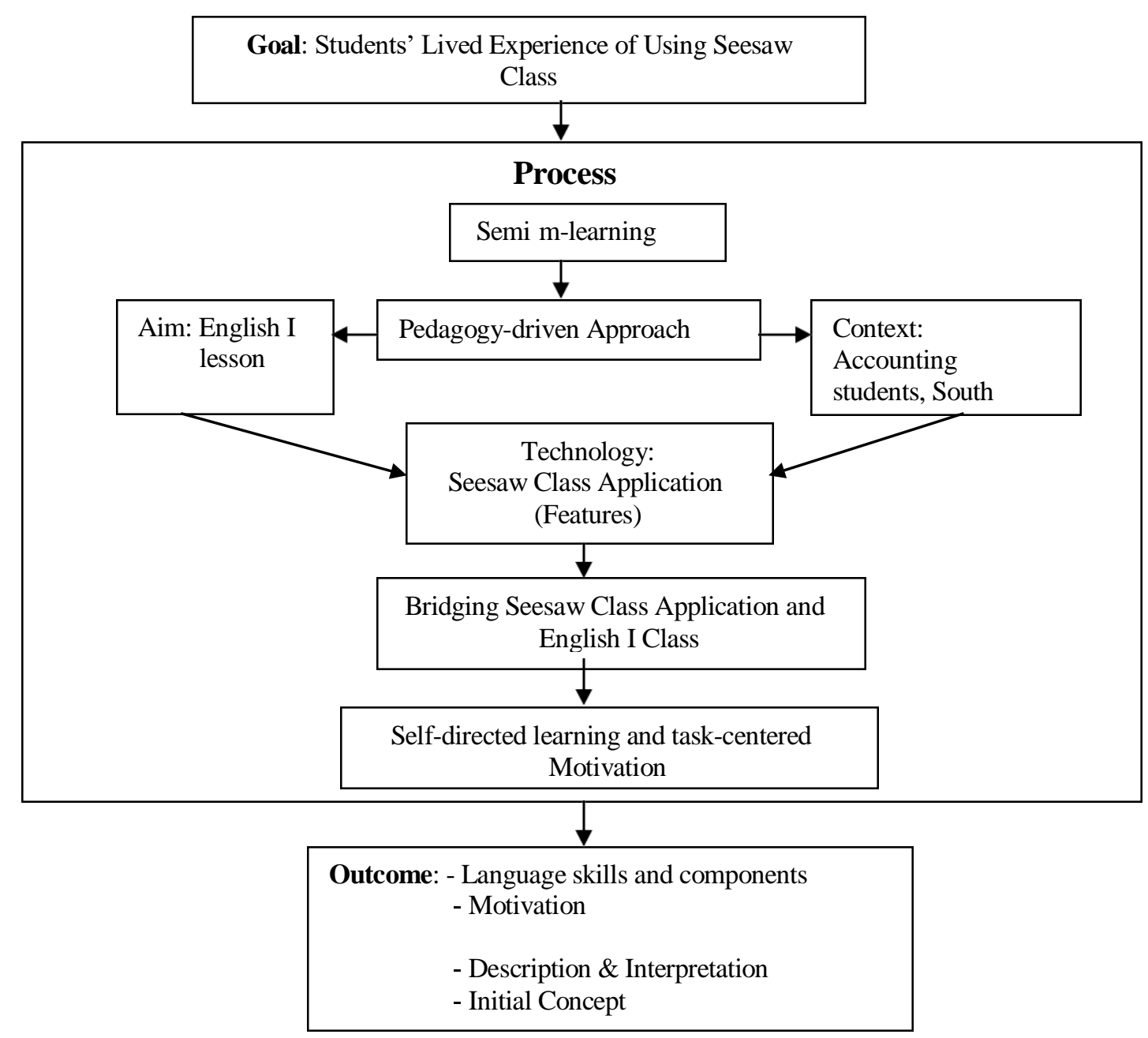

Figure 1. Framework of Pre-Understanding

Based on the framework of pre-understanding, pre-figured themes are formed. There are two types of pre-figured themes, namely empirical themes and transcendent themes. Haller (2014) states that empirical works refer to the fieldworks that are observed from the phenomena. Hence, empirical themes are tangible themes that can be experienced with five senses. Chen (1972) states that transcendent ideas based on Aristotle and Plato refer to the substance of mind and value. Transcendent themes are intangible themes that cannot be experienced with five senses. Empirical themes in this research are flexibility and learning accessibility. Transcendent themes in this research are self-confidence and happiness. There will be also emerging themes that emerge during research process. 


\section{METHOD}

This study is a hermeneutic-phenomenology study. Van Mannen (1990, p. 4) states that "phenomenology describes how one orients to lived experience, hermeneutic describes how one interprets the "texts" of life". This study was conducted in Musi Charitas Catholic University, Palembang, South Sumatera, Indonesia. Two Accounting classes consisting of forty-nine students used Seesaw Class application in English I class. Purposive sampling was used to select the participants of this study in which five participants were chosen.

The instruments in this study were observation, document review, and in-depth interview. Creswell (2012, p.213) defines observation as first-hand information to observe people and place. Document review was focused on the text gathered (Creswell, 2012). Indepth interview was the main instrument in this study. The interview was conducted in oneon-one interview (Creswell, 2012, p. 218). Snowball interview was utilized when interviewing the participants. Triangulation was based on the observation, document review, and in-depth interview.

\section{RESULTS AND DISCUSSIONS}

Themes

Four empirical themes and two transcendent themes that are described and interpreted appear in this study. The empirical themes are flexibility, typing process, learning accessibility, and unsupported features. The transcendent themes are self-confidence and happiness.

\section{Theme 1: Flexibility}

The use of Seesaw Class application makes the students to be able to do their tasks in any place and time. They could also submit their tasks outside the classroom.

"I feel comfortable to use Seesaw Class application since it is embedded in smartphone and I always bring my smartphone and can do my tasks any time and in any place" (Interviewee 1)

The flexibility is also seen through various features installed in the application. The students can submit various types of file. Feedview, calendar view, and class blog are also useful features.

"It helps me since I can insert file, video, link or image in the application for the tasks." (Interviewee 2)

"Feedview gives access to all of the tasks given." (Interviewee 4) 
"The calendar view helps me to see new tasks given." (Interviewee 5)

"The class blog is not only able to be accessed in Seesaw Class application, but it can also be accessed online in the browser with password." (Interviewee 2)

Another case of flexibility is in the terms of installation in smartphone.

"It is easy to install the application and also easy to be used to submit tasks. It also does not take much memory capacity in smartphone." (Interviewee 4)

Flexibility in using Seesaw Class application is seen in three areas. The first is time and place. Students are not restricted in the scope of duration and location in submitting the tasks. It is as stated by Korucu and Alkan (2011, p. 1926) that mobile learning is not placed in a specific location. The second is various file types. The students can create and submit tasks in different file types and they can explore how to use it in the application. It is as stated by Hamilton (2017) that there are various features in Seesaw Class application. The third is installation. The application is easy to be used. Therefore, Seesaw Class application makes teaching-learning process become more flexible.

Theme 2: Typing Process

Since the students are accustomed to write the tasks with paper and pen, typing skill in smartphone with smaller keyboard pad is needed. Some students type the tasks directly in Seesaw Class application and some type in other media firstly. The usual technique to report tasks is by writing in the paper. Students are in the transition process from writing the tasks in the paper into typing the tasks directly in the smartphone media.

"I type my task in smartphone's note first since I am afraid to make mistake and press submit button unconsciously. After that, I move it to the application. (Interviewee 1)

When the students do the tasks in the classroom with the application, they tend to type directly in the application.

"If the tasks are done inside the classroom, I directly type in the application since there is limited time." (Interviewee 2)

"I type directly my tasks in the application since I like typing more than writing in the paper." (Interviewee 4)

Typing process is in the transition process. The students are accustomed to writing in the paper than typing in the application. Thus, the students learn to get used to typing the tasks directly through smartphone media during teaching-learning process. Typing process is an emerging empirical theme. 


\section{Theme 3: Learning Accessibility}

The tasks submitted to the application can be seen by other students since it is online to the students joining the class. Hence, the students can learn English skills and components online.

"I learn from my friends' writing in terms of organizing paragraph of writing and also learn grammar" (Interviewee 4)

"I look at my friends' videos of speaking tasks. I learn how they deliver their speaking and pronunciation" (Interviewee 2)

“I learn vocabulary when I see my friends' writing and speaking." (Interviewee 5)

Learning accessibility makes the students produce language skills in writing and speaking. It is as stated by Carter and Nunan (2001) that writing is focused on creativity and speaking is focused on articulation and self-monitoring. The students also learn language components in grammar, pronunciation, and vocabulary. These language skills and components are as the output in learning with application.

Theme 4: Unsupported Features

Regarding various features in Seesaw Class application, some features do not support the teaching-learning process. The first is in terms of smartphone version.

"I have old version of smartphone. I cannot install the application since the smartphone does not support the application. I submit my tasks by typing first my tasks in my smartphone, and then I send to my friend's smartphone. After that, he inserts my tasks by clicking my name in the application and then puts my tasks there. Sometimes, I submit my tasks with paper" (Interviewee 3)

The second is the process of uploading video and attaching file. There are also unused features in the application.

"When we speak directly from video in the application with front camera, the result is upside down. The maximum time is also only five minutes" (Interviewee 4)

"If we upload the speaking video with add file feature, the maximum file is $50 \mathrm{MB}$. I must compress the video first." (Interviewee 1)

"Adding file is limited only for pdf., jpg., mp4., png. types. I cannot attach doc. type" (Interviewee 2) "I do not use drawing and photo features in the learning process" (Interviewee 1) 
Regarding various features in the application, there are also unsupported features in terms of smartphone and feature specifications. These unsupported features are found during the teaching-learning process. This theme is inside the research, but out of the implementation of learning by using application. This is also an emerging empirical theme.

\section{Theme 5: Self-Confidence}

When the students submit the tasks, they feel confident.

"I feel confident when I submit my writing and speaking online in the application" (Interviewee 5)

The students build self-confidence during the teaching-learning process. It is as stated by Brown (2007, p. 86) that self-esteem is one of cognitive motivation.

Theme 6: Happiness

The students are happy to learn with Seesaw Class application.

"I am happy to learn with the application since I can do and submit the tasks anytime." (Interviewee 2)

Happiness happens when the students utilize application for learning activities. It is as stated by Brown (2007, p. 85) that happiness is one of behavioral motivation. 


\section{Initial Concept}

Based on the analyzed data above, the initial concept discovered in this research can be seen in Figure II below.

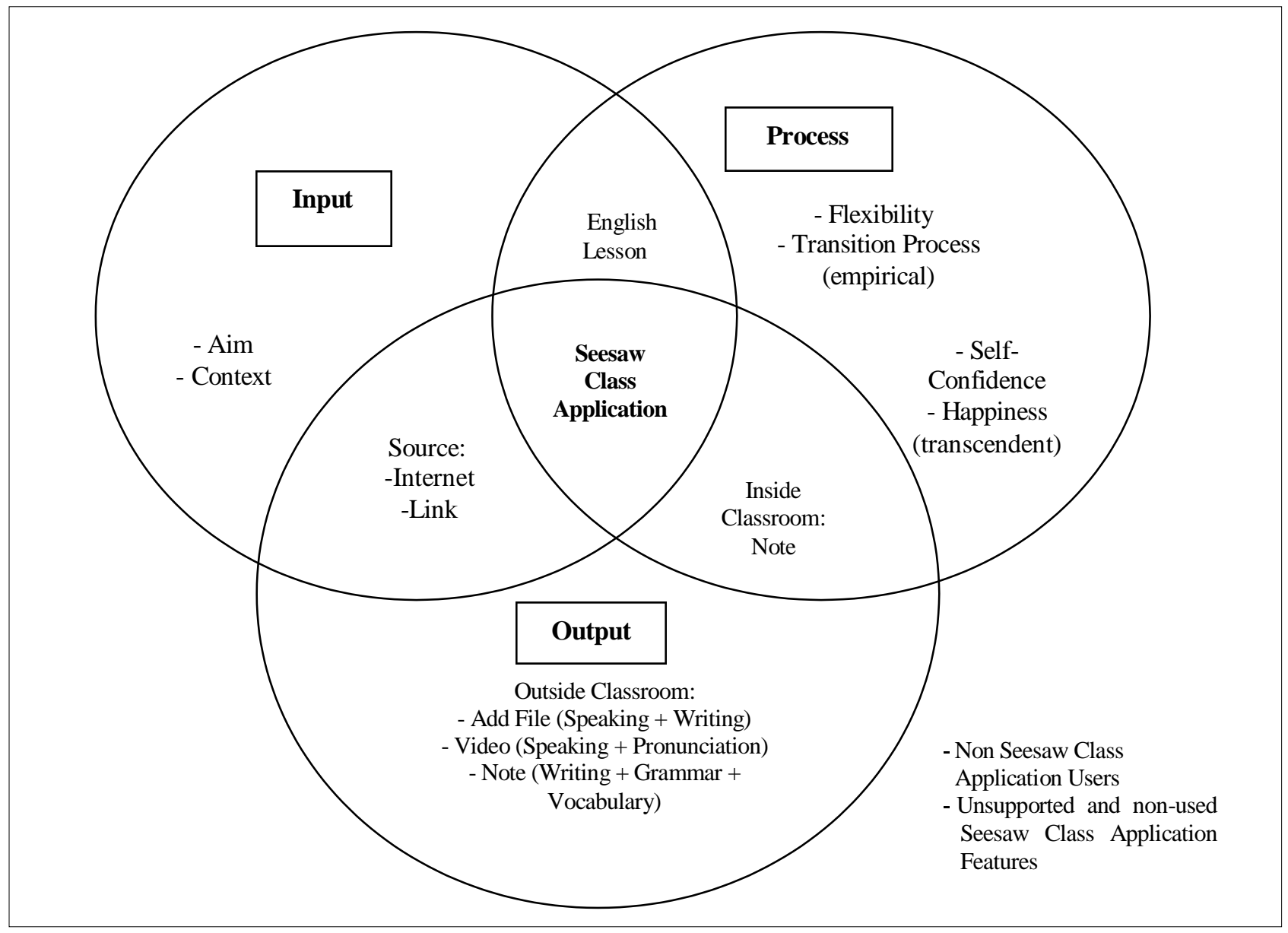

Figure 2. Initial concept discovered in Seesaw Class Application research

Based on the Venn diagram in figure 2 above, three different circle sets indicate input, process, and output. Input is associated with aim and context of learning by using technology. Process is associated with the flexibility and transition process of utilizing technology in language learning as empirical sides and also self- confidence and happiness as transcendent sides. Output is the result of using Seesaw Class application features outside the classroom. Add file feature enhances speaking and writing. Video feature enhances speaking. Note feature enhances writing and grammar. The italic words are the features used in the application. Multiple overlapping circles indicate the relation among the sets. The main overlapping circle is Seesaw Class application circle in which it relates input, process, and output. English lesson overlapping circle relates the input of learning and transition learning 
process in using technology. Source overlapping circle relates input in terms of the use of internet and link feature in application to enhance output of learning. Inside classroom overlapping circle relates the process of using the application inside the classroom as output. From the research, students that do not use Seesaw Class application and the features that are not used in the application are inside the study, but they are outside the implementation of using Seesaw Class application. Hence, they are put outside the circles. Seesaw Class application enhances multiple sets of teaching-learning activities of English I class.

\section{CONCLUSION}

From the research results and discussion above, application in smartphone supports teaching-learning activities. Seesaw class application enhances English language learning in terms of learning flexibility, typing transition, accessibility, and unsupported features. The students utilize the application for language skills in writing and speaking. The students also get exposure of language components in grammar, pronunciation, and vocabulary.

Furthermore, the students get used to having technology as part of their learning. They try to comprehend and use the features in the application. The use of application also triggers students' motivation in the form of self- confidence and happiness. Hence, technology in the form of Seesaw class application and pedagogy in the form of English learning can be drawn in the form of Venn diagram as the initial concept finding. From the Venn diagram, the initial formula of empirical findings (flexibility, typing process, learning accessibility, unsupported features) and transcendent findings (self-confidence and happiness) from this research can be concluded as follows: application in the form of Seesaw class application is part of input, process, and output of learning (application $=$ input $\cap$ process $\cap$ output) and also application and pedagogy blend among input, process, and output (application + pedagogy $=$ input $\cup$ process $\cup$ output). Finally, I believe that technology enhances pedagogy. Technology can be used constantly in language learning in which pedagogy comes first in the form of input in learning aim and context in order to utilize the appropriate technology during teaching-learning process and bring good output in both empirical and transcendent aspects.

\section{ACKNOWLEDGMENTS}

I would like to thank Musi Charitas Catholic University, especially Faculty of Business and Accounting in which I conducted this research. I would also like to thank the students that implemented Seesaw Class Application in English I Class and gave valuable perspective and feedback for this research. I would like to thank Indonesia- Technology Enhanced Language Learning Conference in which I explored more my research during the conference. 


\section{REFERENCES}

Brown, H. D. (2007). Teaching by Principles: An Interactive Approach to Language Pedagogy (3rd ed.). New York: Pearson Education.

Carter, R. \& Nunan, D. (2001). The Cambridge Guide to Teaching English to Speakers of Other Languages. Cambridge: Cambridge University Press.

Chan, N.N., Walker, C., \& Gleaves, A. (2015). An exploration of students' lived experiences of using smartphones in diverse learning contexts using a hermeneutic phenomenological approach. Computers \& Education, 82, pp. 96-106.

Chen, C. (1972). Aristotle and Plato's Theory of Transcendent Ideas. The Society for Ancient Greek Philosophy Newsletter.

Colpaert, J. (2006). Pedagogy-driven Design for Online Language Teaching and Learning. CALICO Journal, 23 (3), pp.477-497.

Creswell, J.W. (2012). Educational Research: Planning, Conducting, and Evaluating Quantitative and Qualitative Research (4th ed). Boston: Pearson Education, Inc.

Haller, B.C. (2014). Theoretical and Empirical Perspectives in Ecology and Evolution: A Survey. BioScience, 64, pp.907-916.

Hamilton, B.J. (2017). Seesaw: A Space for Sharing, Community Building, Feedback, and Formative Assessment.

Korucu, A.T. \& Alkan, A. (2011). Differences between m-learning (mobile learning) and elearning, basic terminology and usage of m-learning in education. Procedia - Social and Behavioral Sciences, 15, 1925- 1930.

Laanpere, M., Pata, K., Normak, P., \& Poldoja, H. (2013). Pedagogy-driven Design of Digital Learning Ecosystems. Computer Science and Information Systems, 11 (1), pp. 419-442.

Ozdamli, F. (2011). Pedagogical framework of m-learning. Procedia - Social and Behavioral Sciences, 31, pp. 927-931.

Schuck, S. (2015). Mobile Pedagogical Framework: a socio-cultural model for mobile learning. Educational Technologies: Now and in the Future.

Sung, Y., Chang, K., Liu, T. (2016). The effects of integrating mobile devices with teaching and learning on students' learning performance: A meta-analysis and research synthesis. Computers and Education, 94, pp. 252-275

Van Mannen, M. (1990). Researching Lived Experience: Human Science for an Action Sensitive Pedagogy. Canada: The University of Western Ontario 
